Evaluating Direct Payments in Residential Care: the perspective of care home providers

Lombard, D. ${ }^{1}$, Wittenberg, R. ${ }^{2}$, Ettelt, S. ${ }^{3}$, Williams, L. ${ }^{3}$, Perkins, M. ${ }^{2}$, Damant, J. ${ }^{2}$, Mays, N. ${ }^{3}$

${ }^{1}$ University of Bristol, Bristol, UK

${ }^{2}$ Policy Innovation Research Unit, Personal Social Services Research Unit, London School of Economics and Political Science, London, UK

${ }^{3}$ Policy Innovation Research Unit, Department of Health Services Research and Policy, London School of Hygiene and Tropical Medicine, London, UK

\begin{abstract}
This paper reports findings from the evaluation of the Direct Payments in Residential Care Trailblazers in England (2014-16). It focuses on the perspective of residential care providers on implementing direct payments, which were aimed at improving the level of choice and control over care available to their residents. The paper explores the views of providers using interviews and survey responses of care home managers and owners. Concerns expressed by providers include issues that have arisen in domiciliary care but also issues specific to residential care, especially challenges in facilitating greater choice and control in settings that provide care collectively for substantial numbers of residents.
\end{abstract}




\section{Evaluating Direct Payments in Residential Care: the perspective of care home providers}

Introduction

In 2012, the Department of Health in England decided to initiate a pilot programme to test the introduction of direct payments in residential care. This followed a recommendation by the Law Commission in 2011, which had advised the Government to consider whether direct payments, then available to pay for domiciliary care and short periods of respite and replacement residential care, could be extended to those requiring permanent long-term residential care (Law Commission, 2011). While the Commission noted that care home residents should have equal access to direct payments and, by extension, improved choice and control over their care, it acknowledged that there were "practical questions concerning the economics of care home provision" that needed to be investigated (Law Commission, 2011: 103). It was also hoped that direct payments would contribute to the Government's agenda of improving the personalisation of care, for which, in domiciliary care, direct payments had emerged to be the main tool.

To address these questions, the Department of Health (now known as the Department for Health and Social Care) invited local authorities with responsibility for adult social services to express their interest in testing the feasibility of direct payments in residential care. The Department chose 20 of those that expressed interest to pilot them and decided to commission an evaluation of the pilots. It required local authorities to liaise with residential care providers in their areas and enlist their support. 
Before the evaluation started, the Department decided to enable all local authorities in England to offer direct payments in residential care from 2016 and rebranded the pilots as 'trailblazers'. The plan was that the remaining local authorities would learn from the experience of the trailblazers and that direct payments would be made available to all residents in care homes from April 2016. However, in 2015, towards the end of the evaluation, the Department decided to postpone the roll-out until at least 2020.

The Department commissioned the Policy Innovation Research Unit (PIRU) to conduct an independent evaluation of the trailblazer programme. The research team comprised a partnership of researchers at the London School of Hygiene and Tropical Medicine and the Personal Social Services Research Unit at the London School of Economics and Political Science. The evaluation took place between January 2014 and June 2016, and the final report was published in 2017 (Ettelt et al., 2017). The aims of the evaluation were to understand how direct payments could be introduced in residential care and to assess the potential impact of direct payments on care home residents, their families, local authorities and care home providers. The implementation of the programme proved slower and more difficult than anticipated: only 71 care home residents accepted the offer of a direct payment and only 40 direct payments were actually implemented in autumn 2015 . This was far less than the 400 or more originally expected by local authorities (Ettelt et al 2017).

The overall aims, methods and findings of our evaluation are presented in the final report of the evaluation (Ettelt et al, 2017). We found significant barriers to implementing direct payments in residential care, including a lack of clarity about the benefits of direct payments to care home residents, especially for older people with 
dementia, a limited range of choices of services for residents, and concerns from providers about the impact of direct payments on their financial sustainability (Ettelt et al., 2017, Williams et al., 2016, Ettelt et al., 2018).

This paper explores in more depth the views and experiences of care home providers. It aims to contribute to the limited literature on the perspective of providers on policy changes concerning residential care by exploring two questions:

1. What were the experiences of residential care providers participating in the Direct Payments in Residential Care Trailblazers?

2. How did care home providers view the effects of direct payments on their homes and on service users and their families?

More specifically, the paper interrogates the perspectives of care home providers in terms of five themes: (1) the motivation of providers to participate in the programme; (2) providers' views on how direct payments were used in their homes; (3) the potential of direct payments to promote personalisation of care in residential settings;

(4) concerns about the financial implications of direct payments for care homes; and

(5) concerns about potential abuse and failure to safeguard residents associated with direct payments. The findings provide insight into the challenges experienced when implementing direct payments in the care home context that may explain, in part, why relatively few direct payments were set up during the trailblazer programme.

\section{Provision and funding of adult residential care in England}


In England, most adult social care is provided to people in their own homes. For people with more severe care needs who are unable to live in their own homes or with family, care homes provide accommodation with either personal care or a combination of personal care and nursing care. There are currently 16,143 care homes in England registered with the national regulator, the Care Quality Commission (CQC, 2017); 83\% of care home beds are provided by homes run by private, for-profit firms, $13 \%$ by the voluntary sector and $4 \%$ by local government or the National Health Service (NHS). Around half of care home residents are funded by their local authority, with the authority purchasing care direct from the providers. However $41 \%$ of care home residents pay for their care themselves as 'self-funders' (CMA, 2017). This is because local authority support for adult social care in England is subject to a financial means test as well as an assessment of support needs against eligibility criteria, and only people with savings below $£ 23,250$ are eligible for local authority-funded care. [The remaining $10 \%$ of care home residents are fully funded by the NHS under 'continuing health care' arrangements that cover people with severe long-term complex health needs.] The direct payment trailblazer programme however related only to residents funded by local authorities.

The care home fees agreed between local authorities and the care homes with which they have contracts vary between local authorities, between care homes and between user groups of services. Local authorities pay higher fees for younger residents (aged 18 to 64) than for older residents (aged 65 and over), enabling more day care activities to be provided for younger residents (NHS Digital, 2017).

Direct payments are defined as 'money given to individuals by social services departments to buy the support they have been assessed as needing' (SCIE, 2005). There are several reasons to expect that direct payments in residential care would 
differ in practice from direct payments in domiciliary care and that the views of providers of residential care would reflect at least some of these differences. Care home residents in general have higher support needs than users of domiciliary care services. For example, almost $70 \%$ of people aged 65 and older living in care homes in England have dementia, compared with less than $6 \%$ of those receiving care in their own homes (Matthews et al., 2013). They are therefore more likely to require assistance to request and manage a direct payment.

Care homes are designed to provide services collectively for groups of residents. On average, care homes have 40 beds, with the optimum size considered to be around 60-70 beds (CMA 2017). Care homes often provide services based on 'block contracts', i.e. long-term contracts with a local authority for a specified number of residents at a fixed rate. They rely on economies of scale: provision of 24-hour care does not require a 1:1 staff to service user ratio in a care home as it does in domiciliary care. Pressures on resources and heavy workloads can leave care home staff unable to spend much time with residents on a one-to-one basis (Talbot and Brewer, 2016, Coughlan and Ward, 2007, McGilton and Boscart, 2006).

The Department of Health provided monies to the local authorities concerned to meet their administrative costs in running their trailblazer schemes, but did not provide resources to enable them to meet higher costs of care: the programme was intended to be cost-neutral other than with respect to administrative costs. A study of the introduction of nursing home vouchers in the Valencia region in Spain found, that the scheme was able to improve residents' choice of service, but that this extension of choice also came at additional costs (Angeles Tortosa and Granell, 2002). Resources for such additional costs were not provided in the English programme. 
More generally, central government reduced its grant allocation to local authorities in England by 37\% in real terms between 2010/11 and 2015/16 (NAO, 2014). As a consequence, almost all local authorities reduced their spending on adult social care, often by freezing, or seeking opportunities to reduce, care home fees. These cuts, along with increasing costs for providers, high staff vacancy rates and the increasingly complex needs of adults in long-term care, have meant that the fee levels set by some authorities for care homes are so low as to be "potentially unsustainable" (NAO, 2016).

Between 2010 and 2015, the number of residential care homes declined by $12 \%$, with 2,444 closures in this period (CQC, 2016: 62). The majority - 59\% - of these homes were small, with ten beds or fewer, which suggests they may have been less resilient to financial pressures. However it is not known to what extent these closures were driven by the cuts to local authority budgets and low rates paid by councils for care home services.

\section{Experience of direct payments in domiciliary care}

In England, direct payments have been introduced in 1995 for a restricted group of service users. Since then, direct payments have become a key method for promoting personalisation in domiciliary adult social care and they are now the Government's 'preferred mechanism' of allocating public funding for adult social care services (Needham, 2011, DH 2014). The idea behind direct payments is that by enabling service users to make their own purchasing decisions, they would be able to select services that best meet their needs and therefore receive a more 'personalised' and cost-effective service (Leadbeater et al. 2008). 
There is a substantial literature on the effects of direct payments on different user groups, indicating that direct payments provide service users with additional choices. Such effects are dependent on a variety of factors, such as the availability of options in the local care market and strategies to support service users in employing their own personal assistants (Arksey and Baxter, 2012, Fernandez et al., 2007, Glasby and Littlechild, 2016). The experience of using direct payments in domiciliary care suggests that younger adults are more likely to benefit from a direct payment than are older people. Older people may also be more reluctant to take up direct payments compared with younger people, and may need more support to manage them (Glendinning et al., 2008, Clark et al., 2004, Woolham et al., 2017).

There is little research on the experience of providers of direct payments, however. When direct payments were introduced in the mid-1990s for some user groups, there was a significant increase in the number of personal assistants employed, leading to concern as to whether the supply and quality of assistants would be able to meet demand (Scourfield, 2005). The restricted availability of qualified paid care workers was a particular problem for service users whose direct payment allowed them to pay for only a small number of hours of care per week (Clark et al., 2004). The evaluation of pilots of individual budgets (a similar concept that aimed to bring together different sources of funding) suggested that many home care providers were reluctant to provide individual budgets (Glendinning et al., 2008). Of those who participated, some were very positive, while others felt that policymakers promoting individual budgets had overestimated the range of choices that could conceivably be made available to users. Other concerns included that the limited amount of money available meant giving additional choices would compromise existing services; that 
users might not pay their bills; and the risk of financial abuse (Glendinning et al., 2008, Manthorpe et al., 2009).

\section{Methods}

This paper draws on a survey of care home managers and owners, interviews with a sub-sample of care home managers and owners in selected areas, and interviews with representatives of national provider organisations. While we specifically focus on the perspectives of providers, the findings are supported by the larger set of data analysed for the evaluation (Ettelt et al., 2017). These include a survey of service users and family members who had accepted or declined the offer of a direct payment, and a follow-up survey after six months of those who had accepted a direct payment; annual interviews with project managers in each participating local authority over three years; face-to-face interviews with local authority staff in five sites selected for in-depth study; interviews with service users and family members accepting or declining a direct payment in these sites; and data on the cost to local authorities of setting up direct payments in residential care (Ettelt et al., 2017).

An online survey of care home providers was conducted between November 2015 and March 2016 to capture the experience of care home managers, owners or other senior care home staff. The survey was aimed at staff from care homes that had participated in the Trailblazer scheme, those that had decided not to participate, and those that expressed interest in participating but did not have a direct payment user at the time.

Questions were derived from analysis of interviews carried out as part of the evaluation, as well as from findings from an initial scoping study and published 
literature (Ettelt et al., 2013). Most questions were quantitative, with a smaller number of open-ended, questions. The survey was piloted by three care home managers. A total of 631 invitations were sent by email to care homes in ten sites (all had been informed about the scheme by their local authority) with a link to the online survey, hosted by online questionnaire provider Survey Monkey. The care home survey questionnaire is available in the appendix of the final report of the evaluation (Ettelt et al, 2017).

One hundred and fourteen responses to the survey were received. After the removal of incomplete responses and responses that indicated misunderstanding of the questions, 85 were included in the analysis, representing a response rate of around $13 \%$. The 85 survey responses related to 70 care homes reporting no direct payment users and 15 care homes reporting one or two direct payment users, reflecting the small scale of the Trailblazers. The characteristics of the care homes can be found in Table 1.

[Table 1 about here]

In view of these small numbers, the results of the survey are presented as cardinal numbers as opposed to percentages. It is not known whether the same care home manages or owners who took part in the interviews also responded to the survey, as the responses from the survey were anonymous.

Sixteen respondents stated they were participating in the scheme in principle but said none of their residents had been offered a direct payment; 12 said they were 
participating but that no resident had accepted a direct payment; 36 said they were not participating. Almost all the non-participating care homes indicated that they had not received information about the direct payment programme from their local authority, despite being in a Trailblazer area (although the local authority believed that it had informed these care homes).

Nineteen semi-structured interviews were conducted with care home managers and owners involved in planning and implementing direct payments across five sites (Table 2). The sites were selected on the basis that they represented different approaches to implementing direct payments in residential care, i.e. as 'full' or 'part' direct payment or both, aimed at different groups of service users such as younger people with physical or learning disabilities or mental health problems or older people. The interviews explored their understanding of the programme, their concerns and thoughts at the beginning of the programme, and their experience of its implementation. (The detailed topic guide is available in the appendix of the final report.)

The interviews involved managers and owners from a variety of care homes of different types and sizes. The smallest home in the sample had places for six residents with moderate learning disabilities, while the largest had capacity for over 100 older people with personal care and nursing care needs. All interviewees were from providers offering residential care, with four offering residential and nursing care; there were local authority-funded residents in all the homes, and some reported that all their residents were funded by the local authority. Eighteen interviewees represented care homes involved in the scheme, while one had decided against participating. Interviewees also received an invitation to participate in the provider survey. 
[Table 2 about here]

Interviews were also conducted with representatives of national stakeholder organisations. There were seven in total, including provider associations from the private and charitable sector (Care England, the National Care Forum and the Registered Nursing Homes Association) and organisations representing service users (Age UK, Carers UK, Alzheimer's Society and SCOPE). Interviews included questions about recent reforms of adult social care, challenges to the sector and the contribution direct payments might make in improving the experience of service users and carers in residential care.

Interviews were conducted face-to-face or over the telephone and recorded with the permission of participants, and later transcribed verbatim. The analysis presented in this paper builds on the themes identified in the final report of the evaluation. These included descriptive categories that aimed to understand how direct payments were implemented in each site (e.g. the number and type of direct payments available; processes for facilitating direct payments; the organisation of the financial transaction; and how direct payments were used), and themes that explored the challenges experienced during the process of setting up and managing direct payments (e.g. information provided about direct payments; approaches to communication and engagement; difficulties setting up direct payments; and concerns about the impacts of direct payments). 
For this paper, these themes were reanalysed to focus on the views and experiences of providers, by bringing together the data collected through the survey and the interviews. Themes that stood out were: (1) the motivation of providers to participate in the programme; (2) providers' views on how direct payments were used in their homes; (3) the potential of direct payments to promote personalisation of care in residential settings; (4) concerns about the financial implications of direct payments for care homes; and (5) concerns about potential abuse and failure to safeguard residents associated with direct payments.

\section{Results}

Motivation of providers to participate in the Trailblazer programme

Care home owners and managers interviewed reported that they agreed with the aim of the Trailblazers to increase 'personalisation' of the care provided in homes. Those catering for older people were particularly supportive, noting that this group of residents was usually offered fewer choices than younger people in residential settings. Managers working in care homes for younger adults also appreciated the opportunity to offer more choice of services, although many suggested that their facilities already offered a substantial number of options to choose from, such as daytime activities.

This positive sentiment was echoed by representatives of provider associations, who argued that it would only be fair if people in residential care had the same access to direct payments as people receiving care in their own homes. 
However, while some managers and owners were happy to support residents who wanted to explore direct payments, others were sceptical as to whether direct payments would be suitable for their residents, for example, older people with advanced dementia.

Some owners and managers viewed participating in the scheme as an opportunity to learn more about direct payments, which they saw as likely to become future policy:

"I'm of the opinion that if something's going to come then I would rather know what's coming than be presented with the finished article and say, 'look, OK, from tomorrow you're doing this'.” (Care home owner 6, Site 4)

However, some had reconsidered their involvement once it became clear that local authorities were unable to provide resources in addition to those already committed to paying providers and that any additional choice in services would have to be funded from within the current care home fee rate.

How direct payments were used in care homes

Trailblazer local authorities settled on three models for offering direct payments, often arrived at in consultation with providers. Four sites adopted the 'full' direct payment approach, where the direct payment comprises the total sum of money allocated to the service user to pay for her/his residential care, typically based on the existing care home fee.

Four sites made only 'part' direct payments available, covering only part of the sum previously paid to the care home. The remainder was then managed by the local authority to pay for the service user's care. This option typically involved local 
authority staff negotiating with care homes whether there was any part of the care home fee that could be used to allow the service user more choice. Four sites chose to offer both 'full' and 'part' direct payments.

Two sites opted for a third model that involved the local authority covering the full cost of the care home fee plus an additional sum of money given to the service user as a direct payment. This option required additional financial investment from local authorities. It was not seen as sustainable beyond the duration of the programme and ceased when the programme ended (Ettelt et al., 2017).

Responses from the provider survey and the interviews suggest that 'full' direct payments were used to pay for the care home services in their entirety (often referred to as the 'care package'). In the survey, four owners and managers stated that they had a resident who paid his / her entire fee (minus any private user 'topups') through a direct payment.

One care home owner, on accepting a 'full' direct payment to pay for a resident's care home fee package, added:

"Whether [the care home fee] comes directly from the local authority to us or whether it [is by] direct payment, that payment is still the same... because care involves your personal care, your continence care, the cleaning of your room, your meals, your laundry, in-house activities that we provide, some outings that we can cost ourselves ... we try not to charge for as much as what we can" (Care home manager 1, Site 12)

In this example the resident had been fully financing the residential care received, but had reached the financial threshold for local authority support. The resident had 
been offered a choice between receiving a direct payment to pay the care home fee in full or having the care home fee paid directly to the care home by the local authority, neither of which resulted in any additional choice.

The most common use of a 'part' direct payment, reported in the survey by ten providers (some of whom had more than one resident with a direct payment), was for individually arranged activities outside the care home $(n=10)$, followed by activities within the care home $(n=4)$. This experience was confirmed in the interviews with managers and owners. Examples of activities paid for by a direct payment included trips to the theatre, meals provided by a local charity within the care home (Site 11), or visits to a garden centre, museum or park, with light meals in cafes (Site 4).

Responses to the survey indicated that some care homes already offered a substantial variety of activities and choice, particularly care homes for younger adults. At interview, a director of a residential care provider with around 100 older residents (across several locations) noted that residents were already given a choice of activities and services, but felt the introduction of direct payments encouraged the care homes to become more creative in the provision of support:

"Because if we are providing a range of things that people don't want, if people are in receipt of a direct payment they will go elsewhere. So it forces our hand to make sure that we change to deliver what people want to receive from us." (Care home manager 3 , Site 7)

The risk of loss of income from a resident with a direct payment proved to be a dilemma for some care homes. They recognised that they would have to improve their choice of services, as a 'part' direct payment would allow the holder to purchase 
services outside the home; but they questioned the sustainability of this option given that the 'part' payment tended to come from the budget that paid the care home fee.

On one occasion, a family considered using a direct payment to continue employing their relative's personal assistant after she (a young disabled person) moved into a care home (Site 6). However, this plan was not realised as the family eventually decided against moving their relative to a care home (their reasons were not reported to the research team). There were, therefore, no cases reported in which a personal assistant was employed in a home.

Potential for direct payments to promote personalisation

Although many managers and owners stated that they agreed with the aim of personalisation, it was not obvious to them that direct payments would lead to more choice and control for residents over their services. For those working with recipients of a 'full' direct payment, it was difficult to see how the direct payment would achieve greater choice and control, even though some family members noted that they enjoyed feeling more in control of the care provided to their family member.

Among those working with recipients of 'part' direct payments, especially younger adults, several indicated that they already offered a substantial number of options especially with regard to activities, thereby offering a good level of personalisation. This tended to be less straightforward for older people. On a positive note, one manager in a home for older people, in which a number of residents received a small additional payment to fund activities (£20/month), explained that his staff had 
developed personal profiles of residents that could be used to discuss possible uses of direct payments.

“...we did the personal profiles, which looked into what was important to them, throughout their life, how we could best support that, within the home anyway? And then, say, for instance, we knew that one of our gentlemen always used to go to a chippy, that he rates the best chippy in [town], so that's on his outcomes, for us to take him there. And, the other lady, that we took to the garden centre, she liked animals...she used to like the garden ... And we asked, we just asked them, we have an idea, and we just say, what do you think?" (Care home manager 6, Site 4)

In this case, participating in the programme provided the inspiration to test other methods of personalising care.

However, for many / most managers and owners of care homes for older people the verdict was less positive. Some respondents feared the direct payments initiative could exacerbate inequalities in adult social care, given the differences between the amount of funding available for younger adults and for older people in residential care.

In addition, some felt that direct payments were blurring the line between the care needs of service users, which are assessed formally and on which funding is allocated, and their 'wants', i.e. their personal preferences that may go beyond these needs. While it was desirable to accommodate the preferences of individuals as much as possible, it was felt by some that the money available did not stretch that far: 
"I think it would be lovely to have a model of social care that everybody could have what they want. But it is down to the budget at the end of the day, and the budget is not there." (Care home manager 2, Site 7)

In a survey response, a manager of a care home, which had three residents holding direct payments covering part of the fee, said that the direct payment system was "based more on want than need", but that funding these 'wants' risked taking away funding that should be used to meet the needs of others:

"Whilst we try hard to ensure everyone gets a range of weekly social activities, this one individual [with a direct payment] gets a much larger range of activities and holidays, in my view, far in excess of what someone of his age range would be experiencing out in 'the world'. My concern is that as increasing amounts of social care money are being used to fund 'wants' for the few, the ability for local councils to fund basic needs for the most will diminish." (Care home manager/owner, Site 11)

This viewpoint was echoed in one interview with an owner of a care home for older people, a registered charity, who explained that the decision not to take part in the Trailblazer programme was mainly driven by discussions with the residents' families, who feared that personalising care, and thus potentially redistributing funding between residents, would undermine the charitable purpose of the home.

"[A local authority officer] came in and explained it all. l'd given the residents' families the paperwork beforehand for them to have a look at, had a conversation with one of them on the phone about it at my home here. But they took the view that [the care home] could be damaged by this, that it's a charity, it's putting all its money back in, has no profit at the 
end of the year, puts all its money back into care. They were concerned there was the potential for [the care home] to be damaged financially, and they said it's like taking... one lady said it's like if somebody on the corner is shaking a tin, it's like grabbing the tin and running off with it - quote, unquote." (Care home manager 4 , Site 8 )

Care home owners and managers also voiced doubts about the potential of direct payments to improve choice and control for those with limited or fluctuating mental capacity to make their own decisions, for example, those with severe learning disabilities, cognitive impairment associated with advanced degenerative disease and older people in the later stages of dementia. While they agreed that individuals should be provided with personalised services, they were not convinced that improved choice could be facilitated by a direct payment. For example, a manager of a home whose residents had advanced dementia suggested that giving people time to dress themselves to the best of their ability would be more desirable than dressing them, yet the latter would be more time-consuming:

"Am I going to let them struggle dressing themselves? That is personalisation in a day-to-day running of a care home, instead of doing everything for them. It is very difficult to explain. A direct payment does not automatically mean, for me, personalisation." (Care home manager 7, Site 4)

In this example, choice was embedded in routine care rather than seen as an additional service that could be purchased alongside usual care. It was seen as a relational aspect of compassionate, good quality care. A manager working with younger adults with learning disabilities also noted that in some circumstances 
choices might need to be simplified to support residents with limited cognitive capacity. Such examples highlighted that, from the perspective of providers, direct payments were not necessarily a suitable means to improve choice and control for all residents, with some choices potentially more compatible with direct payments than others.

Perceived financial risks for care homes

Care home managers and owners were concerned about the potential risks to their finances arising from direct payments. This was a particular problem for homes caring for residents in receipt of a 'part' payment taken from the current care home fee. In some instances, this concern about finances led providers to exit the Trailblazer scheme. In two sites, to ameliorate these concerns, a small additional sum was negotiated with Trailblazer local authorities to be made available as a direct payment. This resulted in the third model of delivering direct payments, involving additional costs for local authorities, described above. However, care home managers with residents receiving a 'full' direct payment felt less at risk, as the resident was expected to cover the care home fee in full with his / her direct payment, although some feared that family members could be tempted to spend the money elsewhere.

The concern about losing money from having residents with 'part' direct payments was also expressed by a representative of a national provider organisation:

"So if a council gives $£ 500$ - I'm just plucking a figure out of the air - to that care home for my place currently, if they now say 'we're going to 
transfer that into a direct payment but, oh, by the way, we've now worked that out and we think that that should be $£ 400$ '. Of course that's going to have an impact. It's going to seriously undermine the business and the person won't be able to pay." (National organisation 7)

The risk of losing money through direct payments was particularly unacceptable to those care home managers and owners who felt that the level of funding received for local authority-supported residents was already below what it cost them to provide the care:

“The direct payment will not make things better for providers. It won't. The only thing that will make things better is if there is a full and honest review of care home fees in an objective, honest, open, transparent way and there is recognition that local authority fees are too low and that the industry has been subsidised by the 40-odd percent of the people who pay private fees." (Care home owner 6, Site 4).

It was not clear how the 'part' direct payment would fit with the current approach to allocating funding, with one care home manager suggesting that the direct payment should be decoupled from the care home fee entirely and provided as an additional payment earmarked for activities. Such an approach is currently more common for younger adults who receive separate funding for day services, but this is typically not available to older people.

One survey respondent noted that delivering direct payments could result in additional administrative costs, for example, due to extra invoicing, and it was not clear who was responsible for these costs. If they were to be taken from the (part) direct payment itself, this would reduce the amount available to service users even 
further. Others, however, noted in interviews that they were already billing service users for additional services and that the same approach could be used for part direct payments. Another owner of a home for older people (Care home owner 6, Site 4) noted that his staff already found it difficult to keep adequate records of essential care provided to residents, reflecting competing demands on their time and attention. Breaking these services into individual elements that could be invoiced separately would require small actions to be scrupulously recorded, which was seen as unrealistic.

'Itemising' care homes bills seemed less of a problem for some of the care homes for younger adults, although here the direct payment related only to day services which the care home had already priced individually, and for which it received separate funding. However, there was similar scepticism in these homes about whether it would be possible and appropriate to break down costs for core services (e.g. personal care) delivered by the homes.

It was also argued that, in the context of the current severe constraints on the level of public funding of care, any approach to personalising services would be more costly than currently provided care, especially for older people whose needs were not always adequately met by the public funding available to them:

"Well, any personalised care could cost more, but then it might cost less in other areas... If you just got the one rate fits all, which it does for older people - far less for younger adults with learning disabilities, of course you will get a far bigger range in terms of what their personal care needs are. But the more that's put in people's hands, they might find ways to be more effective and efficient with their money, but personalised care 
currently, if you just look at the costs of care studies and what's funded, it absolutely means that the costs will have to rise to fund, but it might be different for each person." (National organisation 3)

This concern was echoed by several other home managers and owners who wondered how additional services would be paid for. This was particularly seen as a challenge if direct payment holders were to opt out of services provided communally, for example, meals or laundry. These services would still have to be provided by the care home to other residents, yet without the funding from residents who decided to pay for their own meals or services. The same applied if individuals were to use their direct payment to pay for a personal assistant, as the care home still needed to provide adequate staff cover to comply with minimum staffing requirements:

"They are paying for the hotel costs. They are not paying for care. What if they have a fall? They are in dementia homes. What if two people get into a fight? What if somebody gets really agitated? We have had people waking up one morning saying 'Where am I? Where am I, who are you, how have I got here?' [...] So that requires a lot of one-to-one reassurance, a lot of time. Are we going to bill them separately for that?" (Care home owner 8, Site 4)

\section{Concerns about abuse and safeguarding}

Some managers and owners mentioned their concern about risks of financial abuse and safeguarding, echoing concerns voiced in the domiciliary care sector (Manthorpe et al., 2011). 
The potential for financial abuse of direct payments in residential care was seen as arising from direct payments being used in ways that were not seen to be in the best interests of the resident, either because the resident had made a decision without a complete understanding of the consequences, or because family members opted to decide on behalf the resident, but against the judgement of the care home staff. This concern was particularly voiced by care home managers working with people with cognitive limitations:

"I do feel that you go back into this risk of financial abuse because so many of the residents here are not able to manage their finances. They can't. That's it. It's managed by family members. And it is very difficult for us, I suppose, because if families just provide the basics, who are we to say, you should be providing this, that or the other?" (Care home manager 4, Site 7)

In a hypothetical example, one interviewee expressed concern about residents or family members potentially spending their entire budget on something else (Care home manager 7 , Site 4), if they were given direct payments covering several months' worth of care home fees. Some care home owners and managers feared that the financial risks they faced could be exacerbated by the possibility of residents defaulting on payments to the care home. However, others argued that this would not be so different from working with self-funders, although arguably some of the financial risk was buffered by the higher rates paid by self-funders compared to many local authority funded residents. A small number of managers and owners also wondered whether allowing residents to use their direct payments to pay for personal assistants would threaten their ability to safeguard residents of the home. As one manager pointed out it was initially unclear whether an additional care assistant 
coming into the home would need to be vetted by the home, and to what extent there was a requirement for supervision, so that the home could exercise its statutory responsibilities vis-à-vis the service user employing the assistant and the other residents of the home.

"[If a resident employs a personal care assistant] We have to then look at what the implications are, of them coming into what is our registered service, which we hold the registered manager in responsibilities and accountabilities for, so we would still have to ensure that they've gone through the same processes of DBS [Disclosure and Barring Service] and stuff like that, so it's how that is managed, so that they don't actually put our organisation at risk. And it's also making sure that the CQC [Care Quality Commission] are on board with that, and I know we've been trying to clarify that with CQC." (Care home manager 6, Site 8)

However, during the Trailblazer programme, this problem did not materialise as no personal assistant was employed using a direct payment within a care home.

\section{Discussion}

The survey and interviews of care home managers and owners provide some insight into the perspectives of providers involved in the Direct Payments in Residential Care Trailblazers programme. While they agreed that residential care could, or even should, be more personalised, especially for older people, many care home owners and managers doubted whether direct payments were compatible with the current approach to funding and delivering residential care. Owners and managers agreed 
that direct payments could provide some individuals with enhanced choice and control, for example, in relation to having increased options for day activities. Yet, they also wondered whether direct payments would be able to facilitate meaningful choices for some residents, especially those with limited capacity to make their own decisions and who might rely on others (e.g. family members, carers) to make choices for them.

While some concerns chimed with those voiced in relation to direct payments in domiciliary care (Glendinning et al., 2008, Manthorpe et al., 2009), some issues were specific to residential care, and the ways in which care delivered in care homes is currently funded and organised. Owners and managers worried how direct payments would be implemented in care homes, both with regard to identifying services that residents would want to spend their direct payments on, and in relation to determining the costs of such services (i.e. to produce an 'itemised' bill for each individual with a direct payment). These issues were not relevant to residents with 'full' direct payments, used to pay for the entire care home fee (i.e. the care home 'package'); but it also became clear that this option would be unlikely to provide any additional choice and personalisation to such residents. Although some family members thought that they could use the direct payment as leverage if the needs of service users were not being met, this could not be observed in practice during the trailblazers. In the case of 'part' payments, care homes needed to determine which part of the total fee to release as the direct payment. This appeared to be most straightforward in homes that already costed individual services, although these were mostly activities for younger adults. For other care homes, particularly smaller homes for older people, the task of costing individual services seemed almost insurmountable. 
Care home providers also questioned whether direct payments were compatible with current funding arrangements, both in terms of how care home fees were currently determined and in terms of the lack of financial flexibility within fees for any particular individual placement, given the current reduction in public spending on adult social care. For them, the idea of more flexibility had to be weighed against the potential risks associated with direct payments, echoing earlier observations of risk aversion in the sector (Andrews and Phillips, 2000). More specifically, owners and managers perceived at least three types of risk, perhaps explaining why few decided to participate in the scheme. The first was the risk of losing income from users with a direct payment. This risk could come in two forms: by allowing service users to spend part of the money allocated to them on services provided outside the home (if provided as a part direct payment); or by having to provide more choice in the form of additional or more expensive services, while receiving the same fee (as a full direct payment). The second risk identified by providers related to the possibility of service users or their families misusing the funding provided to them as a direct payment. Such concerns had also been voiced by providers involved in the earlier English social care Individual Budget pilots (Glendinning et al, 2008), although in practice cases of fraud have been rare in social care (Glasby et al., 2009). A third risk was a risk to safeguarding if service users deployed their direct payment in a way that would potentially put them or other residents in the home at risk, again echoing earlier concerns in domiciliary care (Glendinning et al, 2008). This concern was especially mentioned when considering the possibility of allowing residents to employ their own care assistants, with providers wondering how such additional staff would be vetted and supervised if not formally employed by the home. 
Our data do not suggest that any of these risks materialised during the Trailblazer programme. This may be because only 71 offers of direct payments were accepted during its two-and-a-half years. For the 29 direct payments that were still in place in March 2016, 19 were 'full' direct payments, which were used to cover the care home fee in its entirety, thus minimising the financial risk to care homes. To our knowledge, no personal assistant was employed by a resident. Interviews with local authority programme leads and family members, reported elsewhere, also suggested that some providers who were initially supportive opted out of the scheme as the financial risks became clearer to them (Ettelt et al., 2017), although the exact reasons are likely to be varied.

These risks were seen in the context of the financial pressures on the residential care sector. Reporting on the introduction of a nursing voucher scheme in Valencia, Angeles Tortosa and Granell concluded that the scheme could offer more choice but it did so by increasing the costs of care (Angeles Tortosa and Granell, 2002). It seems possible, although this cannot be demonstrated directly, that direct payments would have received a warmer welcome from providers if the financial climate had been less challenging. However, as things stood, most local authorities involved in the Trailblazer programme had little room to allow for any additional spending when embarking on the programme, with only two authorities making small amounts of additional funding available for the duration of the programme in an effort to attract more service users and care homes to the scheme. This raises the question as to whether choice and control in care homes can be improved by way of direct payments without incurring additional costs, which is problematic within a climate of severe funding constraint. 


\section{Conclusion}

The perspective of providers supports the overall conclusion of the Trailblazer evaluation that direct payments did not result in more personalised services in residential care, mostly because of the constraints represented by the financial and organisational arrangements underpinning residential care. Offering direct payments to care home residents would appear to redress the inequity between recipients of domiciliary and residential care identified by the Law Commission (2011) but did not, in practice, significantly improve their scope for greater choice and control.

Providers also identified a number of risks in direct payments, including risks to their financial sustainability and their duty to safeguard residents.

Introducing direct payments in residential care more widely is likely to meet significant resistance from some providers, perhaps particularly so if Government were to introduce 'part' payments at the expense of the existing financial support for the care home fee. 'Full' direct payments may address the financial concerns of providers, but they have very limited potential to improve choice and control for residents. The difficulty of implementing the Direct Payments in Residential Care Trailblazers may have been exacerbated by the prevailing financial climate which had suppressed care home fees over many years, although it is not clear whether, and, at what level, additional funding would make (part) direct payments more acceptable to care homes and more valuable for care home residents. 
This paper is based on independent research commissioned and funded by the NIHR Policy Research Programme through its core support to the Policy Innovation Research Unit (Project No: 102/0001). The views expressed in this paper are those of the authors and are not necessarily those of the NHS, the NIHR, the Department of Health and Social Care, its arm's length bodies or other Government Departments.

The Authors declare that there is no conflict of interest, 


\section{References}

ANDREWS, G. J. \& PHILLIPS, D. R. 2000. Private residential care for older persons: Local impacts of care in the community reforms in England and Wales. Social Policy \& Administration, 34, 206-222.

ANGELES TORTOSA, M. \& GRANELL, R. 2002. Nursing home vouchers in Spain: the Valencia experience. Ageing \& Society, 22, 669-687.

ARKSEY, H. \& BAXTER, K. 2012. Exploring the temporal aspects of direct payments. British Journal of Social Work, 42, 147-164.

CLARK, H., GOUGH, H. \& MACFARLANE, A. 2004. 'It pays dividends': direct payments and older people, Bristol, The Policy Press.

CMA 2017. Care homes market study: final report. https://www.gov.uk/cmacases/care-homes-market-study. London: Competition and Markets Authority.

COUGHLAN, R. \& WARD, L. 2007. Experiences of recently relocated residents of a long-term care facility in Ontario: assessing quality qualitatively. International Journal of Nursing Studies, 44, 47-57.

CQC 2016. The state of health care and adult social care in England 2015/16. London: Care Quality Commission.

CQC 2017. Data for care homes. Available from the website of the Care Quality Commission. http://www.cqc.org.uk/what-we-do/services-we-regulate/care-homes.

ETTELT, S., PERKINS, M., WITTENBERG, R. \& MAYS, N. 2013. Direct Payments in Residential Care Trailblazer Programme evaluation. Preliminary report. London: Policy Innovation Research Unit.

ETTELT, S., WILLIAMS, L., PERKINS, M., WITTENBERG, R., LOMBARD, D., DAMANT, J. \& MAYS, N. 2018. Explaining low uptake of direct payments in residential care: Findings from the evaluation of the Direct Payments in Residential Care Trailblazers. Journal of Social Policy, 47, 505-522.

ETTELT, S., WITTENBERG, R., WILLIAMS, L., DAMANT, J., LOMBARD, D., PERKINS, M. \& MAYS, N. 2017. Evaluation of Direct Payments in Residential Care Trailblazers. Final report. London: Policy Innovation Research Unit.

FERNANDEZ, J.-L., KENDALL, J., DAVEY, V. \& KNAPP, M. 2007. Direct payments in England: Factors linked to variations in local provision. Journal of Social Policy, $36,97-121$. 
GLASBY, J., LE GRAND, J. \& DUFFY, S. 2009. A healthy choice? Direct payments and healthcare in the English NHS. Policy \& Politics, 37, 481-497.

GLASBY, J. \& LITTLECHILD, R. 2016. Direct payments and personal budgets: putting personalisation into practice, Bristol, The Policy Press.

GLENDINNING, C., CHALLIS, D., FERNANDEZ, J., JACOBS, S., JONES, K., KNAPP, M., MANTHORPE, J., MORAN, N., NETTEN, A., STEVENS, M. \& WILBERFORCE, M. 2008. Evalualtion of the Individual Budgets Pilot Programme. Final report. Social Policy Research Unit: University of York.

LAW COMMISSION 2011. Adult social care. Presented to Parliament pursuant to section 3(2) of the Law Commissions Act 1965. London: The Stationary Office.

MANTHORPE, J., STEVENS, M., RAPAPORT, J., CHALLIS, D., JACOBS, S., NETTEN, A., JONES, K., KNAPP, M., WILBERFORCE, M., GLENDINNING, C., MANTHORPE, J., STEVENS, M., RAPAPORT, J., CHALLIS, D., JACOBS, S., NETTEN, A., JONES, K., KNAPP, M., WILBERFORCE, M. \& GLENDINNING, C. 2011. Individual budgets and adult safeguarding: Parallel or converging tracks? Further findings from the evaluation of the Individual Budget pilots. Journal of Social Work, 11, 422-438.

MANTHORPE, J., STEVENS, M., RAPAPORT, J., HARRIS, J., JACOBS, S., CHALLIS, D., NETTEN, A., KNAPP, M., WILBERFORCE, M. \& GLENDINNING, C. 2009. Safeguarding and system change: Early perceptions of the implications for Adult Protection Services of the English Individual Budgets pilots--A qualitative study. British Journal of Social Work, 39, 1465-1480.

MATTHEWS, F. E., ARTHUR, A., BARNES, L. E., BOND, J., JAGGER, C., ROBINSON, L. \& BRAYNE, C. 2013. A two-decade comparison of prevalence of dementia in individuals aged 65 years and older from three functional geographical areas of England: results of the Cognitive Function and Ageing Study I and II. Lancet, 382, 1405-1412.

MCGILTON, K. S. \& BOSCART, V. M. 2006. Close care provider-resident relationships in long-term care environments. Journal of Clinical Nursing, 16, 21492157.

NAO 2014. Financial sustainability of local authorities 2014. London: The Stationary Office.

NAO 2016. Personal commissioning in adult social care. London: National Audit Office.

NHS DIGITAL 2017. Adult Social Care Activity and Finance Report: Detailed Analysis England 2016-17. https://digital.nhs.uk/data-andinformation/publications/statistical/adult-social-care-activity-and-finance-report/adult- 

2018.

SCIE. 2005. SCIE Guide 10. Direct Payments: Answering Frequently asked questions [Online]. Social Care Institute for Excellence.

SCOURFIELD, P. 2005. Implementing the Community Care (Direct Payments) Act: Will the supply of personal assistants meet the demand and at what price? Journal of Social Policy, 34, 469-488.

TALBOT, R. \& BREWER, G. 2016. Care assistant experiences of dementia care in long-term nursing and residential care environments. Dementia, 15, 1737-1754.

WILLIAMS, L., ETTELT, S., PERKINS, M., WITTENBERG, R., LOMBARD, D., DAMANT, J. \& MAYS, N. 2016. Will direct payments make adult residential care more personalized? Views and experiences of social care staff in the Direct Payments in Residential Care Trailblazers. Social Policy \& Administration, early view.

WOOLHAM, J., DALY, G., SPARKS, T., RITTERS, K. \& STEILS, N. 2017. Do direct payments improve outcomes for older people who receive social care? Differences in outcome between people aged $75+$ who have a managed personal budget or a direct payment. Ageing \& Society, 37, 961-984. 